\title{
Colonic mucin: methods of measuring mucus thickness
}

\author{
Vicki Strugala $^{1 *}$, Adrian Allen ${ }^{1}$, Peter W. Dettmar ${ }^{2}$ and Jeffrey P. Pearson ${ }^{1}$ \\ ${ }^{1}$ Department of Physiological Sciences, Medical School, Framlington Place, \\ University of Newcastle upon Tyne, Newcastle upon Tyne NE2 4HH, UK \\ ${ }^{2}$ Reckitt Benckiser Healthcare (UK) Ltd, Dansom Lane, Kingston upon Hull HU8 7DS, UK
}

\begin{abstract}
Mucus is a water-insoluble gel secreted by the gastrointestinal tract. It exists as a protective gel layer adherent to the epithelial surface of the stomach, small intestine and colon. The mucus gel is composed of $1-10 \%(\mathrm{w} / \mathrm{v})$ mucin glycoprotein in a plasma-like fluid. Since the mucus gel is predominantly water, standard histological techniques dehydrate the mucus, making visualisation of the functional barrier difficult. Specialist techniques have been developed to enable visualisation of the intact mucus layer. A simple histological method using snap-frozen tissue, sectioned with a cryostat and stained with modified periodic acid-Schiff's/Alcian blue in mucus-preserving conditions will be described. A second powerful in vivo animal model is described which enables measurement of mucus secretion over time. The use of these two methods has allowed the characterisation of the normal mucus layer in the colon and the determination of how it is affected by disease and dietary intervention, in particular the effect of dietary fibre, and evidence that fibre deficiency results in colonic mucosal fragility is presented.
\end{abstract}

Mucus thickness: Rat colon: Dietary fibre

Mucus is a water-insoluble visco-elastic gel that forms a protective stable unstirred layer over the surface of the gastrointestinal mucosa from the stomach to the rectum. It acts to protect the delicate underlying epithelium from aggressors within the lumen such as gastric acid, digestive enzymes such as pepsin and trypsin, ingested toxins or cocarcinogens, bacterial toxins and enzymes and oxygenderived free radicals (Cross et al. 1984; Allen, 1989). It also provides a lubricating action to aid the passage of food along the gastrointestinal tract, protect the epithelia from mechanical damage and also maintain the mucosa within an aqueous environment, thus preventing desiccation (Allen, 1981; Neutra \& Forstner, 1987). The mucus layer in the colon is colonised by the endogenous microflora and provides an energy source, thus promoting the health of the flora (Garland et al. 1982; Rozee et al. 1982). The microflora protects the host from pathogenic invasion by the process of colonisation resistance (van der Waaij, 1996). In addition, the mucus itself further prevents infection by the mucin molecule mimicking pathogen adhesion sites, thus preventing the bacteria invading epithelial cells (Strombeck \& Harold, 1974; Izhar et al. 1982). Mucus is also a store for co-secreted immunoglobulin A, which further protects the host from pathogenic attack (Neutra \& Forstner, 1987).
The gel-forming properties of mucus are provided by complex mucus glycoproteins, mucins. The mucins make up $10-100 \mathrm{mg} / \mathrm{g}$ wet weight of the mucus gel. Approximately $10 \mathrm{mg} / \mathrm{g}$ mucus gel is composed of dialysable salts of similar composition to plasma, and there is a wide variety of nondialysable solids such as protein, nucleic acid, lipid, food, bacteria, bile, plasma proteins and intrinsic factor (Allen, 1981). However, the mucus gel is predominantly water that may represent $950 \mathrm{mg} / \mathrm{g}$ gel. It is this high water content that was responsible for controversy in the 1980 s as to the existence, or otherwise, of a continuous adherent mucus gel layer in the gastrointestinal tract.

Standard histological techniques remove the water from the tissue and the mucus gel. This dehydration is necessary because these techniques utilise fixation in chemicals such as formalin or glutaraldehyde followed by paraffin embedding of the tissue. Paraffin is not miscible with water, which is replaced by dehydration through a series of graded alcohols into xylene and then to liquid paraffin. After the tissue is sectioned it is rehydrated to allow application of aqueous stains. A final dehydration step to xylene is performed to allow a xylene-based mountant to be applied and a cover slip to be added. These processes remove the adherent mucus gel so that on a standard histological

\footnotetext{
Abbreviations: FD, fibre-deficient; PAS/AB, periodic acid-Schiff's/Alcian blue.

*Corresponding author: Dr Vicki Strugala, present address Reckitt Benckiser Healthcare (UK) Ltd, Dansom Lane, Kingston upon Hull HU8 7DS, UK, fax +441482 582358, email vicki.strugala@reckittbenckiser.com
} 
section of the stomach or colon no adherent mucus layer is present.

Indeed, Morris et al. (1984) observed sections of rat stomach stained with periodic acid-Schiff's/Alcian blue (PAS/AB) after routine fixing in glutaraldehyde and paraffin embedding. They showed that a large amount of the gastric mucosa was not covered in an adherent mucus layer and that $65 \%$ of the remaining patchy layer was $<20 \mu \mathrm{m}$ thick. However, in a similar study in which the gastric mucosa was exposed to damaging agents a continuous mucus layer was observed (Morris et al. 1984). This observation led the authors to conclude that the histological fixing and processing did not damage the mucus layer and, indeed, in normal circumstances the gastric mucosa was not protected by a layer of mucus, as epithelial cells were inherently resistant to damage by acid (Morris \& Wallace, 1981; Morris et al. 1984; Morris, 1985; Wallace, 1989). It was claimed that a mucus barrier was not necessary to protect normal gastric mucosa and only necessary to protect tissues undergoing re-epithelialisation.

A method to visualise the mucus layer on unfixed pieces of tissue was developed by Kerss et al. (1982). The procedure involved sectioning the tissue with parallel razor blades set $1.6 \mathrm{~mm}$ apart, turning the section on to a microscope slide and viewing the mucosa-mucus and the mucusair interfaces using an inverted microscope. This method showed a thick continuous mucus layer in the stomach of the rat, frog and man. Using this method McQueen et al. (1984) were able to demonstrate that the conditions used by Morris and Wallace (Morris \& Wallace, 1981; Morris et al. 1984; Morris, 1985; Wallace, 1989) were destroying the mucus layer; i.e. fixation in $2.5 \%(\mathrm{w} / \mathrm{v})$ glutaraldehyde caused progressive thinning of the mucus layer over a $2 \mathrm{~h}$ period. A key finding was that the thick mucus layer demonstrated by Wallace (1989) over the damaged stomach was a mucoid cap covering the repairing epithelium and the 'mucus' was a fibrin gel containing remnants of mucus and dead cells, and this structure was still present after using standard histological techniques (Sellers et al. 1987). Thus, it is now accepted that a thick protective mucus gel is present across the stomach and the rest of the distal intestinal tract. A continuous mucus layer with a mean thickness of 73, 76 and $192 \mu \mathrm{m}$ was seen in the stomach of the rat, frog and man respectively (Kerss et al. 1982), $82 \mu \mathrm{m}$ over the surface of the rat duodenum (McQueen et al. 1983) and 107, 134 and $155 \mu \mathrm{m}$ in the left colon, right colon and rectum respectively of man (Pullan et al. 1994).

However, although the unfixed section technique allows the intact mucus gel to be seen, it does lack sensitivity due to the large size of the specimens, resulting in poor resolution in the mucosa-mucus interface. In addition, this technique is not easy to apply to the colon as the muscle wall is more flexible, and thus more difficult to cut, and the mucus gel is less robust than in the stomach (Hunter, 1989).

A new method developed by our research group maintains the mucus layer but allows details of the mucosa to be observed; as less tissue is required studies can be performed when tissue is scarce. This method, developed by Jordan et al. (1998), uses snap-frozen unfixed tissue that is sectioned using a cryostat. The sections are stained using modified PAS/AB in mucus-preserving conditions. This method, described in full later (see below), provides an excellent snapshot of the mucus layer and can be provided in any region where biopsies or surgical resection can be obtained. Using the Jordan et al. (1998) method a mean thickness of $144 \mu \mathrm{m}$ was obtained in human gastric antrum biopsies, $176 \mu \mathrm{m}$ in the rat stomach (Jordan et al. 1998) and $15.5 \mu \mathrm{m}$ in the human duodenum (Newton et al. 1998). Thus, this method can be used to determine the effect of disease on the mucus layer.

Clearly, due to the delicate nature of the mucus gel, the best way to assess the mucus layer is in vivo without removing it from its natural environment and promoting dehydration. An in vivo animal model has been developed to allow such measurement. This anaesthetised rat model was initially designed to monitor blood flow in vivo (Holm-Rutili \& Obrink, 1985), but was adapted to measure the mucus gel layer by intravital microscopy (Holm \& Flemström, 1990). This method will be described in full later (see p. 239). Using this method mucus thickness was measured in the rat gastric corpus and was found to be 284 and $221 \mu \mathrm{m}$ at $\mathrm{pH} 2$ and 3 respectively (Schade et al. 1994), and $284 \mu \mathrm{m}$ in the rat duodenum (Sababi et al. 1995). Although technically demanding and requiring specialist equipment, this method has huge advantages in being able to monitor the mucus gel over time and determine the influence of exogenous secretagogues or other interventions. In particular, the use of this method to monitor the effects of NSP in the rat diet will be described.

\section{Materials and methods}

\section{Modified periodic acid-Schiff's/Alcian blue}

Biopsies or pieces of freshly-excised animal tissue were placed in a $1 \mathrm{~cm}^{2}$ envelope of pig's liver, snap-frozen in liquid $\mathrm{N}_{2}$ and stored at $-20^{\circ} \mathrm{C}$ until use. The frozen specimens of tissue were mounted in cryomount embedding medium and $6-18 \mu \mathrm{m}$ thick sections were cut with a cryotome and mounted on to $0.01 \%(\mathrm{w} / \mathrm{v})$ poly-L-lysine-coated microscope slides, allowed to air-dry and stored at $-20^{\circ} \mathrm{C}$.

To determine the thickness of the adherent mucus layer, sections were stained with PAS/AB by a method (Jordan et al. 1998) that retains the full thickness of this layer. PolyL-lysine slides were defrosted and briefly fixed in $100 \%$ ethanol for $10 \mathrm{~min}$, rinsed in slow-running tap water and dipped in $3 \%(\mathrm{v} / \mathrm{v})$ acetic acid. To stain acidic mucins the slides were stained in Alcian blue solution $(1 \%(\mathrm{w} / \mathrm{v})$ Alcian blue $8 \mathrm{GX}$ in $3 \%(\mathrm{v} / \mathrm{v})$ acetic acid, $\mathrm{pH} 2 \cdot 5)$ for $2 \cdot 5 \mathrm{~h}$. After rinsing in $3 \%(\mathrm{v} / \mathrm{v})$ acetic acid, running tap water then deionized water, the slides were oxidised in $1 \%(\mathrm{v} / \mathrm{v})$ periodic acid (aqueous) for $10 \mathrm{~min}$. After rinsing in running tap water, neutral mucins were stained magenta with Schiff's reagent for $15 \mathrm{~min}$. Post rinsing, slides were immersed in three changes of $0.5 \%(\mathrm{w} / \mathrm{v})$ sodium metabisulphite, rinsed and post-fixed in paraformaldehyde vapour at $37^{\circ} \mathrm{C}$ for $45 \mathrm{~min}$. The stained slides were mounted in gelatine and covered with a cover-slip. Chemicals and reagents were obtained from Sigma-Aldrich Co., Poole, Dorset, UK.

Mucus thickness was measured using an inverted light microscope with a calibrated eyepiece graticule. The thickness of the adherent mucus layer was measured 
perpendicular to the mucosal surface from the edge of the epithelium to the outermost part of the mucus layer. Ten measurements were taken per slide every $250 \mu \mathrm{m}$ along the length of the specimen from an arbitrary starting point. Approximately six slides per specimen were measured and a mean obtained.

\section{In vivo anaesthetised rat model}

Experiments were approved by the Home Office under the Animals (Scientific Procedures) Act 1986 (UK Parliament, 1986). Wistar rats of 200-250 g body weight were fasted for $24 \mathrm{~h}$, with water available ad libitum, and anaesthetised with the sodium thiobarbiturate, Inactin $(120-130 \mathrm{mg} / \mathrm{kg}$ body weight intraperitoneally). The body temperature of the rat was maintained at $36-38^{\circ} \mathrm{C}$ using a rectal thermometer and heating blanket. A tracheostomy was performed and the animal was ventilated with room air using a small animal ventilator (Harvard Apparatus Ltd, Edenbridge, Kent, UK). Ringer-bicarbonate solution containing $120 \mathrm{mM}-\mathrm{NaCl}$, $2.5 \mathrm{mM}-\mathrm{KCl}, 25 \mathrm{mM}-\mathrm{NaHCO}_{3}$ and $0.75 \mathrm{mM}-\mathrm{CaCl}_{2}$ was infused into the femoral vein at a rate of $0.6-1.0 \mathrm{ml} / \mathrm{h}$ per $100 \mathrm{~g}$ body weight to prevent acid-base disturbances and dehydration. The femoral artery was cannulated with finebore polyethylene tubing containing heparinised saline $(9 \mathrm{~g}$ $\mathrm{NaCl} / 1 ; 6 \cdot 25 \mathrm{IE} / \mathrm{ml}$ ) to allow arterial blood pressure to be continuously monitored via a pressure transducer and oscillograph (George Washington, USA). A laparotomy was performed and the colon externalised. Approximately $20 \mathrm{~mm}$ of the proximal colon was opened using microelectrocautery. The rat was laid on its left side on a stage and the opened colon placed mucosa side uppermost on to a truncated cone. Mucosa $\left(0 \cdot 5 \mathrm{~cm}^{2}\right)$ was exposed through a hole in a mucosal chamber corresponding to the position of the top of the cone and the junction was made watertight with silicone grease. The tissue was bathed in physiological saline and maintained at $37^{\circ} \mathrm{C}$ with circulating temperaturecontrolled water. The mucosa was trans-illuminated with fibre-optic light and observed using a stereomicroscope (Olympus, Southall, Middlesex, UK). Carbon particles were added to the bathing solution to visualise the mucus layer. A glass micropipette with tip diameter of approximately $2 \mu \mathrm{m}$ attached to a digital micromanipulator was used to measure mucus thickness. Mucus thickness was calculated as:

$$
\text { mucus thickness }=\sin \theta \times \mathrm{D} \text {, }
$$

where $\theta$ is the angle of the micropipette, and D is the distance advanced by micropipette from surface of mucus layer to mucosa.

Colonic mucus thickness was measured in three identical places every $10 \mathrm{~min}$ for $60 \mathrm{~min}$. At this time the mucus layer and bathing solution was removed by suction using a syringe and cannula and stored at $-20^{\circ} \mathrm{C}$. Mucus thickness was measured every $10 \mathrm{~min}$ for a further $60 \mathrm{~min}$. The mucus layer and bathing solution was removed by suction, stored at $-20^{\circ} \mathrm{C}$ and a final mucus thickness measurement made. At the end of the measuring period the animal was killed by an intravenous injection of saturated $\mathrm{KCl}$ solution. The colonic segment and the remaining gastrointestinal tract were removed, snap-frozen and stored at $-20^{\circ} \mathrm{C}$.

\section{Protocol for rat feeding study}

Male Wistar rats with body weight $100-150 \mathrm{~g}$ were kept under standardised conditions of temperature $\left(21-22^{\circ} \mathrm{C}\right)$ and illumination ( $12 \mathrm{~h}$ light-12 h dark). They were allowed 1 week to acclimatise to the conditions before being caged individually. Three different diets were used: a fibredeficient (FD) diet: an ispaghula husk (psyllium)-enriched diet; a control diet with a mixed dietary fibre content (Special Diets Services, Witham, Essex, UK; Table 1). The selected diet of the rats and drinking water were available ad libitum. The rats were fed their selected diets for a period of 4 weeks. The body weight of the rats and the remaining food and water were measured daily between 10.00 hours and 12.00 hours. Stool samples were collected from each rat on a weekly basis and stored at $-20^{\circ} \mathrm{C}$.

\section{ELISA}

Nitro-cellulose membrane (pore size $0.45 \mu \mathrm{m}$ ) supported on blotting paper was wetted and inserted into a minifold seventy-two-well slot blot apparatus (Schliecher

Table 1. Composition and energy content of diets fed ad libitum to Male Wistar rats for 4 weeks

\begin{tabular}{|c|c|c|c|}
\hline Diet & Fibre-deficient & Ispaghula husk-enriched & Control \\
\hline Moisture (g/kg) & 108 & 95 & 100 \\
\hline Crude fibre $(\mathrm{g} / \mathrm{kg})$ & 0 & $3 \cdot 0$ & 145 \\
\hline Crude fat $(\mathrm{g} / \mathrm{kg})$ & 57 & 54 & 43 \\
\hline Crude protein $\mathrm{N} \times 6 \cdot 25 ;(\mathrm{g} / \mathrm{kg})$ & 168 & 188 & 223 \\
\hline $\mathrm{N}$-free extract $(\mathrm{g} / \mathrm{kg})^{\star}$ & 608 & 578 & 512 \\
\hline Digestible energy (MJ/kg) & $14 \cdot 04$ & $13 \cdot 88$ & $12 \cdot 80$ \\
\hline Metabolisable energy (MJ/kg) & $12 \cdot 64$ & $12 \cdot 49$ & $11 \cdot 50$ \\
\hline Total NSP $(\mathrm{g} / \mathrm{kg}) \dagger$ & $3 \cdot 0$ & 137 & 154 \\
\hline Insoluble NSP (g/kg)† & $1 \cdot 0$ & 19 & 135 \\
\hline Soluble NSP $(\mathrm{g} / \mathrm{kg}) \dagger$ & $2 \cdot 0$ & 119 & 18 \\
\hline Soluble:insoluble & $2: 1$ & $6 \cdot 3: 1$ & $0 \cdot 1: 1$ \\
\hline
\end{tabular}

*Starches, polysaccharides and simple sugars together with some dietary fibre.

†Determined by the Englyst procedure (Englyst et al. 1994). 
and Schuell, Dassel, Germany) and connected to a vacuum source. Standards and samples were added to individual wells and allowed to absorb onto the membrane under vacuum. The nitro-cellulose membrane was removed from the apparatus and placed into a container and ELISA performed. To block non-specific binding the membrane was incubated in PBS containing $2 \%(\mathrm{w} / \mathrm{v})$ bovine serum albumin overnight at $4^{\circ} \mathrm{C}$. The membrane was incubated in primary antibody diluted in $1 \%(\mathrm{w} / \mathrm{v})$ bovine serum albumin in PBS at room temperature for $2 \mathrm{~h}$. Unbound antibody was removed by rinsing in two changes of $0.5 \%(\mathrm{v} / \mathrm{v})$ TWEEN 20-PBS followed by three changes of PBS. Horseradish peroxidase conjugated secondary antibody diluted in $1 \%(\mathrm{w} / \mathrm{v})$ bovine serum albumin in PBS was added and incubated for $1.5 \mathrm{~h}$. After rinsing as described previously, colour was developed with $0.05 \%(\mathrm{w} / \mathrm{v}) 3,3^{\prime}$-diaminobenzidine in $0.03 \%(\mathrm{v} / \mathrm{v})$ $\mathrm{H}_{2} \mathrm{O}_{2}$ in PBS for $5 \mathrm{~min}$. After rinsing in tap water the membrane was dried and absorbance read at $595 \mathrm{~nm}$ using a scanning densitometer (Shimadzu, Milton Keynes, Bucks., UK).

\section{Haemoglobin assay}

Oxyhaemoglobin and deoxyhaemoglobin were determined by measurement of absorbance at $575 \mathrm{~nm}$ and $560 \mathrm{~nm}$ respectively (UV/Vis spectrophotometer; Phillips, Cambridge, $\mathrm{UK})$. A standard curve was produced using rat haemoglobin $(0-300 \mathrm{mg} / \mathrm{l})$ and haemoglobin concentration was expressed as $\mathrm{mg} / \mathrm{l}$.

\section{Atomic absorption}

Fe content was determined by atomic absorption at a wavelength of $248.3 \mathrm{~nm}$ using an Fe lamp and an Atomic Absorption Spectrometer model 3300 in conjunction with AA Winlab software version 2.61 (Perkin Elmer Instruments, Beaconsfield, Bucks., UK). Calibration was performed using $\mathrm{Fe}$ standards (BDH, Poole, Dorset, UK) diluted in saline $(0-2 \mu \mathrm{g} / \mathrm{l})$.

\section{Statistical analysis}

Data are expressed as means with their standard errors, unless otherwise stated. Data were analysed using unpaired Student's $t$ test and were considered significant when $P<0 \cdot 05$.

\section{Results}

Mucus thickness in the proximal rat colon using the in vivo method ranged from 213 to $1486 \mu \mathrm{m}$, with a mean mucus thickness of 642 (SE 54.8) $\mu \mathrm{m}$ ( $n$ 34; Fig. 1). After removal of the colonic mucus layer by suction a layer of gel that was resistant to removal remained firmly adherent to the epithelium. The mean thickness of this firmly adherent mucus layer was $101(\mathrm{SE} 6 \cdot 2) \mu \mathrm{m}$ with a range of 43-201 $\mu \mathrm{m}$ ( $n$ 40; Fig. 1). Colonic mucus was constitutively secreted at a rate of $3.4 \mu \mathrm{m} / \mathrm{min}$ ( $n$ 19). After the mucus was removed by suction the secretion rate was augmented to $5 \cdot 6 \mu \mathrm{m} / \mathrm{min}$

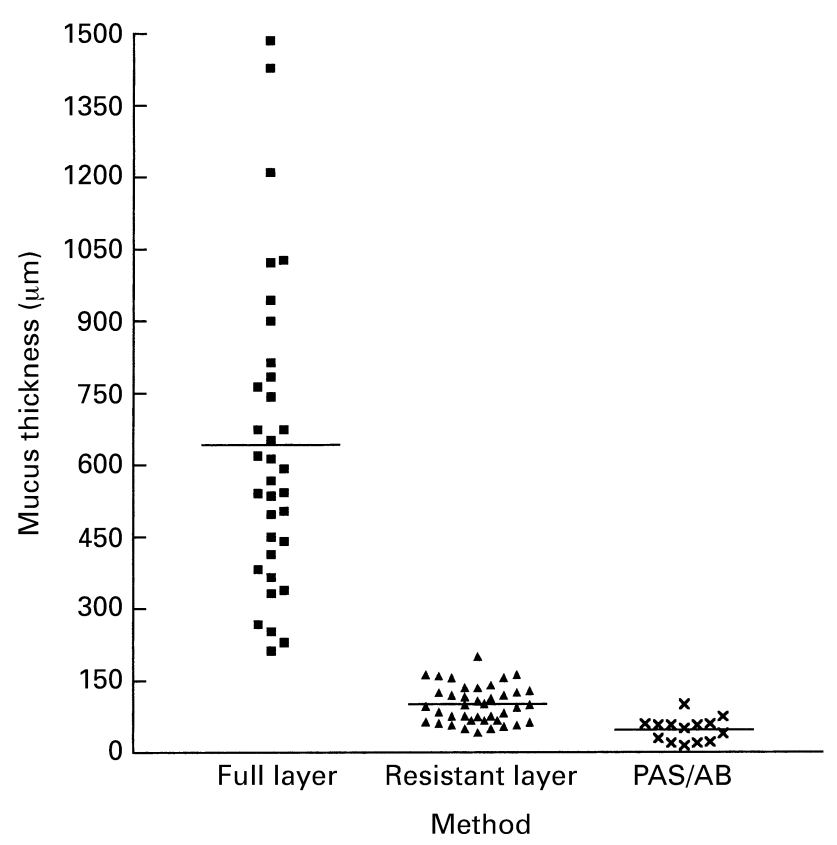

Fig. 1. Mucus thickness values in the rat colon as measured in the anaesthetised rat in vivo and by periodic acid-Schiff's/Alcian blue (PAS/AB) staining of cryostat sections. ( $\boldsymbol{\square})$, Full thickness of colonic mucus layer in vivo; ( $\mathbf{\Delta})$, thickness of firmly-adherent mucus layer after removal of the sloppy mucus layer by suction in vivo; $(\mathrm{X})$, mucus thickness in PAS/AB-stained cryostat sections; (-), mean mucus thickness. Mean thickness was 642 (SE 55) $\mu \mathrm{m}$ ( $n$ 34) for the fullthickness mucus layer, 101 (SE 6.2) $\mu \mathrm{m}$ ( $n$ 40) for the firmly-adherent mucus layer remaining after suction and 47.5 (SE 6.5) $\mu \mathrm{m}(n$ 13) for PAS/AB-stained cryostat sections.

( $n$ 17) for a period of approximately $60 \mathrm{~min}$ before returning to basal secretion rate.

Cryostat sections of rat colonic tissue, fasted overnight, were stained using the PAS-AB method of Jordan et al. (1998). An essentially continuous mucus layer was observed that stained purple with PAS-AB, indicating a high content of acidic mucins. In the proximal rat colon mucus thickness values ranged from 0 to $350 \mu \mathrm{m}$ with a mean thickness of 47.5 (SE 6.5) $\mu \mathrm{m}$ ( $n$ 13; Fig. 1). These data compare favourably with the thickness of the layer resistant to removal in vivo.

The in vivo anaesthetised rat method was used to measure mucus thickness in the colon of animals fed one of three different diets: an FD diet; a control diet containing $154 \mathrm{~g}$ $\mathrm{NSP} / \mathrm{kg}$; an ispaghula husk-enriched diet containing $137 \mathrm{~g}$ $\mathrm{NSP} / \mathrm{kg}$ as assessed by the Englyst procedure (Englyst $e t$ al. 1994; Table 1). The effect of NSP on the mucus layer is discussed in detail by Brownlee et al. (2003), we focus on the additional information obtained by using the in vivo anaesthetised rat model that would not have been found using an alternative method.

Whilst monitoring mucus thickness in the group of rats fed the FD diet a substantial amount of bleeding was observed. There was no obvious cause for this bleeding and it was not observed in the two groups fed the fibrecontaining diets. It was also noticed that the bleeding did not stop or clot readily, leading to a build up of blood and 
plasma exudate in the bathing chamber. This finding led us to investigate this phenomenon further.

A semi-quantitative four-point visual scale was used to compare mucosal bleeding between the three feeding groups: 0, no visual evidence of bleeding; 1, mild, small bleed that clots quickly $(<2 \mathrm{~min}) ; 2$, moderate, one to two areas of bleeding that clot slowly ( $>2 \mathrm{~min}) ; 3$, severe, three or more areas of bleeding that clot slowly ( $>2 \mathrm{~min})$. The mean score for the FD group was $2 \cdot 1$ (SE $0 \cdot 3$ ) compared with $0 \cdot 1(\mathrm{SE} 0 \cdot 1)$ and 0 (SE 0) for the ispaghula and control group respectively $(P<0 \cdot 001)$.

To obtain more objective evidence that the FD rats were having more mucosal bleeding, the amount of fibrin and fibrinogen released into the bathing solution was measured. This measurement was done using an ELISA with a polyclonal rabbit anti-human fibrinogen antibody and rat plasma fibrinogen as a standard. This method demonstrated that significantly more fibrin and fibrinogen were present in the bathing solution of FD animals $(45 \cdot 2(\mathrm{SE} 7 \cdot 1) \mu \mathrm{g} ; n$ 6) than in ispaghula-fed animals $(26.9$ (SE 4.1) $\mu \mathrm{g} ; n 9, P=0.014)$ and control animals $(27 \cdot 2$ (SE 3.3) $\mu \mathrm{g} ; n 8, P=0 \cdot 010)$. In addition, using immunohistochemistry with the same antifibrinogen antibody, positive staining was seen throughout the mucosa, lamina propria and luminal aspect of fibredeficient colonic tissue, whereas in animals fed fibre no staining was evident. Mean fibrinogen content in faecal homogenates was significantly greater in FD rats $(12 \cdot 3$ (SE $1.5) \mu \mathrm{g} / \mathrm{g}$ stool dry weight; $n$ 8) than in ispaghula-fed animals $(6 \cdot 4$ (SE 1.6) $\mu \mathrm{g} / \mathrm{g}$ stool dry weight; $n 12, P=0 \cdot 020)$.

The amount of haemoglobin present in the bathing solution of FD rats was significantly higher than in ispaghula-fed rats $(242(\mathrm{SE} 37) \mathrm{mg} / \mathrm{l}(n 7) v .77(\mathrm{SE} 10) \mathrm{mg} / \mathrm{l}$ ( $n$ 12); $P=0 \cdot 026)$. Fe concentration was significantly higher in FD rats than fibre-fed rats. Mean Fe concentration was $0 \cdot 45(\mathrm{SE} 0 \cdot 04) \mu \mathrm{g} / \mathrm{l}$ in FD rats $(n 10), 0 \cdot 31(\mathrm{SE} 0 \cdot 02) \mu \mathrm{g} / \mathrm{l}$ in ispaghula rats $(n 14 ; P=0.003)$ and $0.23(\mathrm{SE} 0 \cdot 01) \mu \mathrm{g} / \mathrm{l}$ in control rats $(n 3 ; P=0 \cdot 013)$.

\section{Discussion}

It is clear that the adherent mucus layer can be observed and measured when the correct conditions are used. When using methods that prevent dehydration of the aqueous mucus gel a thick continuous mucus layer is present in the stomach and the colon. We have used two methods to demonstrate that the rat colonic mucus layer is in fact composed of two functionally-distinct gels. The epithelium is covered by a firm adherent mucus layer that is resistant to removal by suction and shear, thus providing an effective barrier to lumen aggressors such as bacterial and digestive enzymes and toxins. Above this layer is an extensive secretion of a sloppy mucus layer that can be removed by suction and therefore acts as a lubricant to aid the passage of the stool along the intestine.

Cryostat-sectioned tissue stained with modified PAS/AB is a simple method that can be applied to a wide range of tissue types, enabling characterisation of the normal mucus layer and the effect of disease on this layer. However, the in vivo anaesthetised rat model, although complex and requiring specialist techniques, provides a vast amount of information regarding the dynamics of mucus secretion. It provides more than a mere snapshot image; it allows measurement over time in a physiological status with blood flow, peristalsis and nervous inputs all intact. There is great opportunity to use this model to investigate the effect of physiological and pharmacological intervention on the mucus and mucosa.

We have utilised this method to investigate the effect of dietary fibre supplementation on the colonic mucus and mucosa. In the present study additional unexpected results were obtained because we were able to visualise the colonic mucosa in vivo. It was apparent that the mucosa of rats fed an FD diet was fragile and prone to spontaneous bleeding. Using a snapshot histological method this characteristic would not have been observed, and the further evidence of mucosal damage in FD rats discussed here would not have been obtained.

Speculation as to why the colonic mucosa of FD rats should be prone to bleeding and damage is manifold. One possible mechanism involves the increased contact of the mucosa with potentially damaging lumen agents. A lack of NSP in the diet will reduce the size of the stool, both due to lack of bulk and lack of bacterial proliferation (Stephen \& Cummings, 1979; Nyman \& Asp, 1982; Nyman et al. 1986; Cummings et al. 1992). There will also be an increase in colon transit time (Cummings et al. 1976), leading to an increase in water absorption that results in the already small stool becoming even harder and smaller (Burkitt et al. 1972). Under normal conditions toxins, carcinogens, secondary bile acids and enzymes are diluted in the stool contents and rapidly evacuated. In the absence of NSP these potentiallydamaging molecules have more chance of coming into contact with the epithelium and causing damage.

A lack of short-chain fatty acids in the colon could be responsible for the increased mucosal damage seen in the absence of dietary NSP. Butyrate is the preferred energy source for colonocytes (Clausen \& Mortensen, 1995) and can provide approximately $6.3 \mathrm{~kJ}(1.5 \mathrm{kcal}) / \mathrm{g}$ (Davidson \& McDonald, 1998). Butyrate is proposed to contribute to the health of the colon and has a trophic effect. An increased uptake of butyrate promotes the repair processes necessary to protect the integrity of the cells, including increasing cell proliferation rates and regulating mucosal cell growth (Davidson \& McDonald, 1998). NSP fermentation to shortchain fatty acids has been shown to increase the colonic crypt cell production rate (Goodlad et al. 1989) and direct infusion of butyrate can also increase mucosal DNA content, stimulate colonocyte cell division and may increase mucosal blood flow (Spiller, 1994). Thus, the lack of shortchain fatty acids, and butyrate in particular, may have profound effects on the health of the colonic mucosa.

A deficiency of vitamin $\mathrm{K}$ may be a consequence of reduced NSP intake by rats. A characteristic behaviour of the rat is the act of coprophagy, or re-ingesting their own faeces, which provides the rats with a valuable source of vitamin $\mathrm{K}$ (Waynforth \& Flecknall, 1992). In the absence of NSP the stool weight and output is reduced (Cummings, 1993) and so the potential for coprophagy is also reduced, which could lead to vitamin $\mathrm{K}$ deficiency. In addition, menaquinone (vitamin $\mathrm{K}$ ) is synthesised by some Gram-positive gut bacteria, and daily requirements for dietary vitamin $\mathrm{K}$ increase from 10 to $25 \mu \mathrm{g} / \mathrm{kg}$ in germ-free rats and vitamin $\mathrm{K}$ 
deficiency can be induced experimentally with powerful antibiotic treatment (Bentley \& Meganathan, 1982). Reduced faecal concentrations of enteric menaquinone-producing bacteria and symptoms of vitamin $\mathrm{K}$ deficiency have previously been observed in rats fed low-fibre diets (Mathers et al. 1990).

In the present study the bleeding sites that occurred in the colonic mucosa of the FD rats did not clot easily, pointing towards a defect in the blood-clotting cascade. Vitamin $\mathrm{K}$ is an important cofactor in blood clotting and is involved in the hepatic synthesis of at least four protein clotting factors, including prothrombin (Bowman \& Rand, 1980). If FD rats have a vitamin $\mathrm{K}$ deficiency the production of vitamin $\mathrm{K}$ dependent clotting factors will be reduced and so the bloodclotting cascade may become impaired. An increase in prothrombin clotting time and reduction in plasma concentration of vitamin K-dependent clotting factors has previously been observed in rats fed a low-fibre diet (Mathers et al. 1990). However, as the changes were only observed in a single animal in their study, further studies are required to confirm whether vitamin $\mathrm{K}$ deficiency occurs in FD rats, leading to increased mucosal fragility. The studies will involve investigation of prothrombin clotting times, blood-clotting ability and assessment of levels of vitamin K and clotting factors in the blood.

In conclusion, the present study shows that a lack of NSP in the diet after 4 weeks of feeding makes the colonic mucosa more fragile and prone to damage. In the physiological situation damage to the mucosa from the passage of the stools might be expected. Thus, a diet containing NSP, or dietary fibre, is necessary for the maintenance of a healthy colonic mucosa.

\section{References}

Allen A (1981) Structure and function of gastrointestinal mucus. In Physiology of the Gastrointestinal Tract, pp. 617-639 [LR Leonard, editor]. New York: Raven Press.

Allen A (1989) Gastrointestinal mucus. In Handbook of Physiology - The Gastrointestinal System, vol. 3, pp. 359-382 [JG Forte, editor]. Bethesda, ML: American Physiological Society.

Bentley R \& Meganathan R (1982) Biosynthesis of vitamin K (menaquinone) in bacteria. Microbiological Reviews 46, 241-280.

Bowman WC \& Rand MJ (1980) Textbook of Pharmacology. Oxford: Blackwell Scientific Publications.

Brownlee IA, Havler ME, Dettmar PW, Allen A \& Pearson JP (2003) Colonic mucus: secretion and turnover in relation to dietary fibre intake. Proceedings of the Nutrition Society 62, 245-249.

Burkitt DP, Walker ARP \& Painter NS (1972) Effect of dietary fibre on stools and transit times, and its roles in the causation of disease. Lancet ii, 1408-1411.

Clausen MR \& Mortensen PB (1995) Kinetic studies in colonocyte metabolism of short-chain fatty acids and glucose in ulcerative colitis. Gut 37, 684-689.

Cross CE, Halliwell B \& Allen A (1984) Antioxidant protection a function of tracheo-bronchial and gastrointestinal mucus. Lancet i, 1328-1330.

Cummings JH (1993) The effect of dietary fiber on faecal weight and composition. In Handbook of Dietary Fiber in Human Nutrition, pp. 263-349 [GA Spiller, editor]. Boca Raton, FL: CRC Press.
Cummings JH, Bingham SA, Heaton KW \& Eastwood MA (1992) Faecal weight, colon cancer risk, and dietary intake of non-starch polysaccharides (dietary fiber). Gastroenterology 103, 1783-1789.

Cummings JH, Hill MJ, Jenkins DJA, Pearson JR \& Wiggins HS (1976) Changes in fecal composition and colonic function due to cereal fiber. American Journal of Clinical Nutrition 29, $1468-1473$.

Davidson MH \& McDonald A (1998) Fiber: forms and functions. Nutrition Research 18, 617-624.

Englyst HN, Quigley ME \& Hudson GJ (1994) Determination of dietary fibre as non-starch polysaccharides with gas-liquid chromatographic, high-performance liquid chromatographic or spectrophotometric measurement of constituent sugars. Analyst 119, 1497-1509.

Garland CD, Nash GV \& McMeekin TA (1982) The preservation of mucus and surface-associated microorganisms using acrolein vapor fixation. Journal of Microscopy - Oxford 128, 307-312.

Goodlad RA, Ratcliffe B, Fordham JP \& Wright NA (1989) Does dietary fibre stimulate intestinal epithelial cell proliferation in germ free rats? Gut 30, 820-825.

Holm L \& Flemström G (1990) Microscopy of acid transport at the gastric surface in vivo. Journal of Internal Medicine 228, 91-95.

Holm-Rutili L \& Obrink KJ (1985) Rat gastric mucosal microcirculation in vivo. American Journal of Physiology 11, G741-G746.

Hunter AC (1989) Mucus and mucosal bicarbonate in the gastrointestinal tract. $\mathrm{PhD}$ thesis, University of Newcastle upon Tyne.

Izhar M, Nuchamowitz Y \& Mirelman D (1982) Adherence of Shigella flexneri to guinea pig intestinal cells is mediated by mucosal adhesion. Infection and Immunity 35, 1110-1118.

Jordan N, Newton J, Pearson J \& Allen A (1998) A novel method for the visualization of the in situ mucus layer in rat and man. Clinical Science 95, 97-106.

Kerss S, Allen A \& Garner A (1982) A simple method for measuring thickness of the mucus gel layer adherent to rat, frog and human gastric mucosa: influence of feeding, prostaglandin, $\mathrm{N}$-acetylcysteine and other agents. Clinical Science 63, 187-195.

McQueen S, Allen A \& Garner A (1984) Measurement of gastric and duodenal mucus gel thickness. In Mechanisms of Mucosal Protection in the Upper Gastrointestinal Tract, pp. 215-219 [A Allen, editor]. New York: Raven Press.

McQueen S, Hutton D, Allen A \& Garner A (1983) Gastric and duodenal surface mucus gel thickness in rat: effects of prostaglandins and damaging agents. American Journal of Physiology 245, G388-G393.

Mathers JC, Fernandez F, Hill MJ, McCarthy PT, Shearer MJ \& Oxley A (1990) Dietary modification of potential vitamin K supply from enteric bacterial menaquinones in rats. British Journal of Nutrition 63, 639-652.

Morris GP (1985) The myth of the mucus barrier. Gastroenterologique Clinique et Biologique 9, 1006-1107.

Morris GP, Harding RK \& Wallace JL (1984) A functional model for extracellular gastric mucus in the rat. Virchows Archive 46, 239-251.

Morris GP \& Wallace JL (1981) The roles of ethanol and of acid in the production of gastric mucosal erosions in rats. Virchows Archive 38, 23-38.

Neutra MR \& Forstner JF (1987) Gastrointestinal mucus: synthesis, secretion, and function. In Physiology of the Gastrointestinal Tract, vol. 2, pp. 975-1009 [LR Johnson, editor]. New York: Raven Press.

Newton J, Jordan N, Pearson JP, Allen A \& James OJ (1998) Thinning of the adherent gastric antral and duodenal mucus gel layer in H. pylori positive subjects with advancing age. Gut $\mathbf{4 2}$, A80. 
Nyman M \& Asp N-G (1982) Fermentation of dietary fibre components in the rat intestinal tract. British Journal of Nutrition 47, 357-366.

Nyman M, Asp N-G, Cummings JH \& Wiggins H (1986) Fermentation of dietary fibre in the intestinal tract; comparison between man and rat. British Journal of Nutrition 55, 487-496.

Pullan RD, Thomas GAO, Rhodes M, Newcombe RG, Rhodes GT, Allen A \& Rhodes J (1994) Thickness of the adherent mucus gel on colonic mucosa in humans and its relevance to colitis. Gut $\mathbf{3 5}$, 353-359.

Rozee KR, Cooper D, Lam K \& Costerton JW (1982) Microbialflora of the mouse ileum mucous layer and epithelial surface. Applied and Environmental Microbiology 43, 1451-1463.

Sababi M, Nilsson E \& Holm L (1995) Mucus and alkali secretion in the rat duodenum - effects of indomethacin, N-omega-nitro-Larginine, and luminal acid. Gastroenterology 109, 1526-1534.

Schade C, Flemström G \& Holm L (1994) Hydrogen ion concentration in the mucus layer on top of acid-stimulated and acidinhibited rat gastric mucosa. Gastroenterology 107, 180-188.

Sellers LA, Allen A \& Bennett MK (1987) Formation of a fibrin based gelatinous coat over repairing rat gastric epithelium after acute ethanol damage: interaction with adherent mucus. Gut $\mathbf{2 8}$ $835-843$.

Spiller RC (1994) Pharmacology of dietary fibre. Pharmacology and Therapeutics 62, 407-427.

Stephen AM \& Cummings JH (1979) Water-holding by dietary fibre in vitro and its relationship to faecal output in man. Gut 20, $722-729$.

Strombeck DR \& Harrold D (1974) Binding of cholera toxin to mucins and inhibition by gastric mucins. Infection and Immunity 10, 1266-1272.

UK Parliament (1986) Animals (Scientific Procedures) Act. London: H.M. Stationery Office.

van der Waaij D (1996) The nature and function of interactions between the intestinal microflora and the host. In Inside Story: A Guide to the Intestinal Microflora, pp. 17-23. Place of publication: Yakult, Nederland B. V.

Wallace JL (1989) Gastric resistance to acid: is the 'mucusbicarbonate barrier' functionally redundant? American Journal of Physiology 256, G31-G38.

Waynforth HB \& Flecknall PA (1992) Experimental and Surgical Technique in the Rat. London: Academic Press Ltd. 